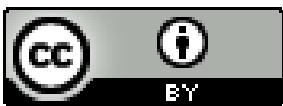

\title{
DOSSIÊ TEMÁTICO RELAÇÕES ÉTNICO RACIAIS E CURRÍCULO/FORMAÇÃO DE PROFESSORES/AS
}

\author{
Eugenia Portela de Siqueira Marques ${ }^{1}$ \\ Rosana Batista Monteiro ${ }^{2}$
}

A publicação deste dossiê ocorre em meio a pandemia causada pelo Covid-19, corona vírus. As aulas nas escolas, universidades e faculdades públicas e privadas em quase todo o país foram suspensas. Ao mesmo tempo em que a saúde pública enfrenta certamente um dos maiores desafios deste século, a educação, as Ciências Humanas continuam a sofrer ataques pelo atual governo do Brasil. A população negra, maioria nas periferias das cidades são as mais ameaçadas pela pandemia pelo alto grau de vulnerabilidade em que vivem, trabalham, estudam.

Quais serão as consequências do quadro que vivemos para as crianças, adolescentes, jovens e adultos, especialmente as negras e negros? Onde e com quem estão as crianças e adolescentes que dependem da escola como espaço não apenas de aprendizagem, mas de suprimento de suas necessidades básicas como a alimentação? $\mathrm{Na}$ educação superior, pública e privada, qual a situação de estudantes cotistas ou bolsistas, pobres, negros e negras? Não poderíamos imaginar quando este dossiê foi proposto que estaríamos vivendo o agravamento de uma crise já instalada no país.

\footnotetext{
${ }^{1}$ Pós-Doutora em Educação pela UFPR. Doutora em Educação pela UFSCar e Mestre em Educação pela Universidade Católica Dom Bosco (2004). Docente na Universidade Federal de Mato Grosso do Sul (UFMS). Líder do Grupo de Estudos e Pesquisas sobre Educação, Relações étnico-raciais e Formação de professores - GEPRAFE. Coordenadora do GT 21 ANPED- Educação e Relações étnico-raciais, gestão 2020-2021. https://orcid.org/0000-0003-3182-171X. E-mail:_portelaeugenia@gmail.com

2 Doutora em Educação (UFSCar), e Mestre em Educação (UNICAMP). Pedagoga. Docente do Departamento de Ciências Humanas e Educação (DCHE) e do Programa de Pós-graduação em Estudos da Condição Humana - (PPGECH) da Universidade Federal de São Carlos (UFSCar É líder do Grupo de Pesquisa em Educação, Territórios Negros e Saúde (ETNS). Pós-doutoranda no Programa de Pósgraduação em Relações Étnico-raciais no CEFET/RJ (2019 - 2020). https://orcid.org/0000-0003-16728912. E-mail: rosanabmonteiro@ufscar.br
} 
A situação vivida neste momento coloca novos desafios à educação de modo geral e para uma educação antirracista em específico. Este Dossiê, uma parceria entre o GT 21 - Educação e Relações Étnico-Raciais/ANPED e Associação Brasileira de Pesquisadores (as) Negros (as) - ABPN quando foi proposto tinha como objetivo refletir sobre a educação das relações étnico-raciais no currículo e na formação de professores e professoras. Este é um desafio contínuo de pesquisadores e pesquisadoras, militantes, docentes que permanentemente estão engajados na construção de uma sociedade mais igualitária e justa em que a educação escolar tem papel primordial. Refletir continuamente sobre as relações étnico-raciais no currículo e na formação de professores e professoras visa possibilitar que estes profissionais, dentre os quais nos incluímos, contribuam para a construção de estratégias de implementação das Diretrizes Curriculares Nacionais para a educação das relações étnico-raciais e para o ensino de história e cultura afro-brasileira e africana.

Como afirma Silvério (2015, p.) em relação a formação de professores e professoras, as DCNERER, trazem orientações para que se desfaçam “... a mentalidade racista e discriminadora secular; para a necessidade de superar o etnocentrismo europeu; para a desalienação dos processos pedagógicos; para a construção de projetos pedagógicos, e pedagogias, que desvendem os mecanismos racistas e discriminatórios..." sendo seu objetivo central a reeducação das relações étnico-raciais.

Neste sentido, os artigos que compõem este Dossiê resultantes de pesquisas, de aprofundamentos teóricos, de reflexões sobre práticas pedagógicas, na educação básica e no ensino superior, tendo como eixo central as relações étnico-raciais e o currículo e/ou a formação docente são ainda mais necessários diante do contexto atual.

O dossiê é composto por oito textos de autores e autoras do campo das relações étnicoraciais que atuam e/ou pesquisam currículo e formação de professores.

O texto de Luiz Fernandes de Oliveira, "Opção decolonial e antirracismo na educação em tempos neofascistas", se inicia apresentando as ameaças que o atual governo de ultradireita, eleito em 2018, faz não somente as políticas e programas de ação afirmativa, mas também a tantas outras políticas que garantem direitos sociais arduamente conquistados. O autor chama de "o espectro" aquele(s) tem quem rondado "as questões raciais e o antirracismo na educação brasileira" ameaçando de revogar as políticas aprovadas nos últimos anos. E, por isto, seu texto chama nossa atenção a necessidade de "aprimorar a organização e aprofundar as contradições para construir 
uma nova consciência, ou seja, continuar o que fizemos sempre, mas com mais rigor teórico e mais militância". Ao discutir a ameaça à lei 10.639/2003, lembrando ainda que brevemente o percurso de sua aprovação e regulamentação pelas Diretrizes Curriculares Nacionais para a Educação das Relações Étnico-raciais, destaca a palavra de Amauri Pereira para quem as ações educativas e debates acerca do "racismo e antirracismo, [...] só foi possível devido a presença direta ou indireta de militantes ou profissionais engajados nas lutas antirracistas (Pereira, 2013). Para Fernandes “... é o fato de explicitar a militância, a dedicação organizada em ações múltiplas, a insurgência cotidiana que educa gerações e corações, a desobediência epistêmica e política, muito além do aspecto formal escolar ou acadêmico". Entremeando o texto com relatos de experiências, suas e de outras pessoas, educadores militantes, e a análise pautada na perspectiva decolonial e antirracista, nos apresenta a pedagogia antirracista e luta antirracista nas escolas e universidades e nos propõe três níveis de intervenção insurgente. $\mathrm{O}$ autor traz elementos constitutivos da cultura afro-brasileira para refletirmos e nos desafia perguntando: "por que não aprendemos a desenvolver um trabalho político insurgente semelhante aos processos de resistências e afirmações de nossos ancestrais?"

A professora Ana Ivenicki nos apresenta uma densa reflexão sob o título "Perspectivas multiculturais para o currículo de formação docente antirracista". A autora aborda a formação de professores, inicial ou continuada, na perspectiva pós/decolonial e multicultural com o objetivo de contribuir para reflexões acerca do currículo que considere "o desafio ao preconceito com relação a identidades étnicoraciais marginalizadas". Preocupa-se com a relação entre currículo e a formação das identidades docentes em perspectiva não essencializada e se propõe a refletir considerando as interseccionalidades. Para Ivenicki o "olhar multicultural pode representar contribuição relevante na discussão sobre as relações étnico-raciais e as perspectivas antirracistas no currículo e na formação de professores". Considerando as pedagogias críticas multiculturais que questionam visões coloniais e hegemônicas, aborda exemplos de pesquisas em que se questionam os conteúdos "universais" carregados de noções heteronormativas, que desconsideram gênero, reforçam as desigualdades, e que estão presentes em currículos de cursos de formação de professores em Artes, Música e Matemática. Observa que há inclusões curriculares da perspectiva multicultural fracas e fortes e que dificilmente se constituem como 
emancipatórias de fato. Busca caminhos para propor um outro currículo, especialmente para a formação de professores. Por fim, nos faz refletir ainda sobre os desafios de pensar o currículo e a formação de professores considerando "a identidade como híbrida, transitória e fluida".

$\mathrm{O}$ texto "Relações raciais na escola: entre legislações e coordenações pedagógicas” de Wilma de Nazaré Baía Coelho e Sinara Bernardo Dias discorre sobre a importância das legislações que fundamentam a educação para a educação das relações étnico-raciais, entre as quais as Leis $\mathrm{n}^{\circ}$. 10.639/03, a lei $\mathrm{n}^{\circ}$ 11.645/08, a Resolução CNE/CP N 01/2004, o Parecer CNE/CP N 03/2004, as DCNERER e o Plano Nacional de implementação destas Diretrizes. As autoras afirmam que as coordenações pedagógicas das escolas possuem um papel fundamental na efetivação do aparato legal para a educação. Defendem que ao poder público cabe a responsabilidade de consolidar agendas propositivas junto a gestores e técnicos das gestões municipais, estaduais e federal, a fim de que sejam dados mecanismos e estratégias para o desenvolvimento dessas orientações como política de Estado e, que a formação de professores contemplem a diversidade racial na construção histórica da cultura do país. Ao considerarem que as representações negativas construídas sobre o negro e sua cultura, no interior do ambiente escolar, pode gerar a discriminação e a negação das diferentes identidades, indicam que a construção de uma identidade negra positiva é um desafio para a escola. Isto porque o imaginário pedagógico que identifica os negros e sua cultura de maneira desigual e institucionalizada, mesmo após os avanços decorrentes das legislações, demonstra as dificuldades que permeiam o cotidiano escolar. Nesse contexto, as atribuições e ações que cabem às coordenações pedagógicas, com relação educação para as relações raciais, e os desdobramentos das suas práticas pedagógicas são basilares para os procedimentos da escola, bem como a mobilização e ação desse profissional pode fortalecer o desenvolvimento de ações que contemplem o respeito à temática por toda a comunidade escolar.

Perspectivas Transnacionais da Diversidade Étnico-Racial e Cultural na formação de professores das autoras Tatiane Cosentino Rodrigues, Ivanilda Amado Cardoso e Flávia Francchini apresenta dados parciais de pesquisa em andamento cujo objetivo é mapear o debate teórico sobre a questão da diversidade étnico-racial e cultural, em diferentes contextos nacionais e visa identificar o lugar da diversidade cultural no campo da formação de professores de forma articulada entre Brasil, França e 
EUA. Segundo as autoras, o artigo se alia ao trabalho que está sendo desenvolvido no âmbito de dois outros projetos, do Programa Abdias Nascimento/CAPES, edital que contemplou com bolsas de mobilidade nove estudantes de graduação e doutorado autodeclarados negros da UFSCar com pesquisas na Colômbia, França e EUA e à pesquisa em desenvolvimento, financiada pelo CNPq/Edital Universal, intitulada "Transnacionalismo e proposta curricular para a educação das relações étnico-raciais e da diferença no ensino". Destacam que no caso brasileiro, as pesquisas demonstram que o preconceito e discriminação raciais são parte do cotidiano de crianças, jovens e adultos/as que frequentam as escolas. As práticas discriminatórias se iniciam na educação infantil, continuam no primeiro e segundo ciclos do ensino fundamental, persistindo no ensino médio. Na França, por décadas a legislação escolar não conferiu tratamento específico às singularidades dos públicos escolares, sejam elas linguísticas, culturais ou étnico-raciais. A partir da década de 1990, os estudos sobre discriminação ainda focados na dimensão do gênero e deficiência desenvolveram-se no contexto francês, evitando termos como raça/racial. O texto sinaliza que a discussão sobre educação e diversidade étnico-racial nos EUA possui um histórico de décadas devido ao processo de mobilização e reorganização do sistema educacional empreendidos pelo movimento dos direitos civis. Os estudos étnicos comparativos são dedicados ao entendimento do conceito de diversidade ao redor do globo, compreendendo as diferenças culturais, políticas, estéticas, religiosas, econômicas e o significado de etnia em diferentes Estados.

A discussão sobre o desafio posto a educação brasileira que objetiva inserir a história e cultura africana, afro-brasileira e indígena na educação básica, numa perspectiva intercultural e decolonial, a partir da implementação das leis $\mathrm{n}^{\mathbf{o}}$. 10.639/2003 e n ${ }^{\circ}$. 11.645/2008, foi feita por Eugenia Portela de Siqueira Marques e Valéria A.M.O Calderoni, no texto, "A implementação das diretrizes curriculares nacionais para a educação das relações étnico-raciais: subversão à lógica da colonialidade no currículo escolar". As reflexões apresentadas no artigo problematizam as barreiras e as disputas no campo do currículo para a efetivação de uma pedagogia intercultural e decolonial. Com base em pesquisa realizada com educadores, em escolas públicas da educação básica, as autoras apresentam um panorama de escolas investigadas em Mato Grosso do Sul, onde os professores vivenciam as tensões próprias das práticas pedagógicas decoloniais. Além dos possíveis 
avanços e perspectivas no processo de implementação destas legislações, as autoras apontam que estas legislações promoveram desacomodações e inquietações ao currículo monocultural. Demostram também que o mito da democracia racial está presente em muitos depoimentos e a proposta de um currículo decolonial acaba sendo diluída nos discursos da "diversidade" e da "igualdade", que não problematizam a diferença, reforçando, assim, o imaginário social e a pedagogia do "silenciamento". Reconhecem a necessidade de ressignificação e desconstrução da herança colonial no que tange as lógicas epistêmicas outras, as quais se fazem diferentes da lógica ocidental.

$\mathrm{O}$ artigo "Apontamentos e bases epistemológicas entre formação docente e currículo: desafios contemporâneos para uma educação antirracista”, de Ana Cristina Cruz propõe um debate sobre currículo e formação docente a partir da Educação das Relações Étnico-Raciais e o ensino de história da África e afro-brasileira. O texto se debruça sobre os temas contidos na publicação do IX volume da Coleção História Geral da África da UNESCO. Apresenta um histórico dos desafios colocados na Coleção História Geral da África pela UNESCO (HGA) na década de 1960 cuja publicação foi foco de uma mudança de orientação internacional sobre o lugar da África e do legado intelectual, cultural, estético e político do continente africano na história global. Tal processo ocorreu junto a um reposicionamento de reivindicações no âmbito da Organização das Nações Unidas (ONU) sobre o continente africano. O texto avança ao indicar as problemáticas ainda correntes na abordagem sobre a história do continente africano que se limitam ao colonialismo e a escravização de crianças, mulheres e homens africanos negros. De igual maneira, a análise apresenta apontamentos sobre as mudanças epistemológicas e metodológicas que têm sido verificadas com a entrada de perspectivas em diversas áreas, e o texto dá destaque na pesquisa em educação. Em seguida, o texto apresenta possibilidades e inovações colocados a partir do uso do conceito de diáspora, na medida em que as experiências de deslocamentos, migração e diáspora na contemporaneidade, abrem a possibilidade de análises que respondam ao tempo presente. $\mathrm{O}$ artigo finaliza com o debate teórico sobre a proposta conceitual presente no IX volume da Coleção História Geral da África da Africanité globale [“Africanidade global”]. De acordo com a autora, a partir dos debates realizados pela comissão estabelecida pela UNESCO para a elaboração e concepção do nono volume, o conceito propõe uma ruptura epistemológica ao incorporar as diversas formas de dispersão da africanidade na longa duração e em sua diversidade. A proposta delineada 
no artigo é de que a "Africanidade global" trata de uma espécie de genealogia da experiência das populações africanas e seus descendentes no espaço da diáspora. Por fim, a autora articula o debate com os desafios do tempo presente de modo a necessidade de articular as lutas colocados pelos conflitos sociais em nossas sociedades de modo a fazer frente ao atual modelo global que se espraia em torno da gestão social neoliberal e suas implicações em sociedades estruturalmente racializadas.

$\mathrm{O}$ artigo "O PIBID como estratégia de implementação das DCNERER nos espaços da formação docente do Pedagogo, na universidade e nas escolas" das autoras Rosana Batista Monteiro e Bárbara Cristina Sicardi Nakayama, apresenta a experiência do Núcleo Pedagogia do PIBID, na Universidade Federal de São Carlos, campus Sorocaba em articulação com a educação das relações étnico-raciais. O PIBID, Programa Institucional de Bolsas de Iniciação a Docência, criado em 2007 no âmbito da CAPES vem se consolidando como espaço de formação inicial e continuada de professores (as) articulando os cursos de licenciatura e as escolas. As autoras apresentam o lugar e importância da formação docente nas políticas de ação afirmativa, especialmente nas Diretrizes Curriculares Nacionais para a educação das relações étnico-raciais (Res. CNE/CP 01/2004) e reconhecem nas DCN de Formação de professores e de Pedagogia, certa atenção à diversidade. Assim, afirmam que "DCN de Formação de Profissionais do Magistério (BRASIL, 2019) e às DCN da Pedagogia referem que se deve considerar na formação docente as questões relativas à diversidade étnico-racial" dentre outras. Apresentam o compromisso da UFSCar com a formação de profissionais, dentre esses os professores(as), para que "respeitem às diferenças, valorizem a diversidade e que combatam as desigualdades" e como este princípio se reflete no projeto institucional do PIBID UFSCar e, em particular no subprojeto do Núcleo Pedagogia, no campus Sorocaba. A maior contribuição do artigo está na descrição e análise dos projetos desenvolvidos por bolsistas do curso de Pedagogia, elaborados sob a perspectiva do trabalho colaborativo, interdisciplinar e antirracista. Os resultados referem-se a aprendizagens em torno da reeducação das relações raciais (e outras) entre professores(as) das escolas, bolsistas, estudantes do ensino fundamental, supervisoras e coordenação. A organização e desenvolvimento dos projetos exigiu de bolsistas, supervisoras e da coordenação pesquisar os conteúdos, estratégias e materiais relacionados a história e cultura afro-brasileira e africana, mobilizando a todos(as) na busca de referenciais teóricos e didático-pedagógicos. Para as autoras, o Núcleo 
propiciou a implementação das DCNERER nas escolas e na universidade. $O$ reconhecimento pelos resultados expressou-se no convite para integrar uma exposição no $2^{\circ}$ Fórum de Relações Raciais e Educação/SEDU, Sorocaba.

Por fim, o artigo "Currículo negro, Asè e Sankofa: perspectivas, cotidianos e valores afro-civilizatórios" de Ana Cristina da Costa Gomes e Luciana Ribeiro Oliveira articula duas pesquisas de mestrado, realizadas pelas autoras, e que se complementam positivamente. As autoras propõem a construção de um currículo negro que considere as "trajetórias de mulheres negras, pesquisadoras e ativistas da educação étnico-racial". Ao evidenciar essas trajetórias as autoras acabam por fazer uma importante homenagem a professora e pesquisadora Azoilda Loretto da Trindade, reconhecendo o legado por ela deixado após seu falecimento precoce. Apresentam o percurso histórico do movimento negro até a aprovação da legislação que torna obrigatório o ensino de história e cultura afro-brasileira e africana observando a luta e as estratégias de negros e negras para se educarem e educarem os seus. Destacam, retomando as contribuições de Azoilda Trindade, os valores civilizatórios afro-brasileiros e defendem a sua importância na organização do currículo e das vivencias na escola. Os valores civilizatórios, de acordo com as autoras "nos remetem a conhecimentos e práticas oriundas nas culturas africanas, embora dissolvidos pelo processo diaspórico". São valores civilizatórios: Memória, Oralidade, Circularidade, Axé, Ludicidade, Musicalidade, Cooperatividade, Religiosidade, Ancestralidade, Corporeidade. O texto segue com a descrição e análise dos dados empíricos das pesquisas, em que se observou o currículo em ação, o desenvolvimento de atividades que buscaram, em alguma medida, construir um currículo negro, respaldado nos valores civilizatórios afro-brasileiros.

Este dossiê reúne um importante conjunto de textos produzidos por pesquisadoras e pesquisadores, atuantes na formação docente, inicial e continuada, e/ou nas escolas, alterando currículos na perspectiva dos princípios delineados pelas leis de ação afirmativa. Desejamos a todos e todas, uma boa leitura. 